\title{
Strategic Alliances
}

\section{Managing the Dynamics of Fit}

\author{
Marc U. Douma, Jan Bilderbeek, Peter J. Idenburg and \\ Jan Kees Looise
}

This article presents a framework for structuring and supporting the complex and dynamic process of alliance building. Fit is the key concept in this framework, which is based on an extensive literature study and in-depth case studies. The concept of "fit" is not new in itself. The added value of this article is, firstly, that it identifies different aspects of fit and their interrelationships, as well as providing an insight into the drivers for fit. Here, we focus on strategic and organisational fit in particular. Secondly, we make practical recommendations for alliance managers on how to actually manage fit. (c) 2000 Elsevier Science Ltd. All rights reserved.

\section{Introduction}

Dubbed a passing fad up until a few years ago, strategic alliances now form a vital part of today's business environment. The recent e-business revolution has boosted alliance activity even further. Yet, if we look at the facts, a word of caution seems to be needed. Alliance results are often disappointing, and some companies are still struggling on the path into the new alliance era. In this article we present a framework which can support managers in managing the dynamic process of alliance building. This framework is based on the concept of fit. We will demonstrate that proactively managing a good fit between alliance partners, instead of focusing on individual benefits, could make the difference between fit and failure!

\section{Strategic alliances: a key competitive tool!?}

Finding a large multinational, or even a medium-sized, national firm without any strategic partnerships is not easy. Only a few years ago, strategic alliances were considered to be a temporary
Marc U. Douma was at the time of writing of this article a senior consultant at

PricewaterhouseCoopers in The Netherlands (Utrecht office). He received his Ph.D. from the University of Twente on his research into strategic alliances. E-mail: marc.douma@nuon.com

Jan Bilderbeek is professor of financial management and business economics at the School of Technology and Management, University of Twente, The Netherlands.

Peter J. Idenburg is currently 
Dean of the School of

Technology, Policy and

Management and Professor of

Strategic Management at Delft University of Technology, The

Netherlands. At the time of the writing of this article, he was also a professor of strategic management at the University of Twente, The Netherlands.

Jan Kees Looise is Professor of Human Resource Management at the School of Technology and Management, University of Twente, The Netherlands. phenomenon. However, the opposite has turned out to be true. Every major company, be it Microsoft, Philips or Unilever, is involved in several strategic alliances. During the nineties, changes took place in the alliance landscape. Due to the everincreasing pace of technological developments and access to new technologies, alliances have become a key success factor in many industries.

This has led to a shift from 'traditional' cost-driven alliances to knowledge-intensive alliances, where inter-partner learning is a major objective. ${ }^{1}$ The traditional view that strategic alliances are no more than a stepping stone towards full integration, and consequently towards loss of identity and independence, no longer holds true. Recent research reveals that only a very small percentage (less than 5 per cent) of alliances eventually lead to a merger or acquisition. ${ }^{2}$ Alliances, therefore, are a vital part of our new economy and are an organisational form in themselves. Many companies are now part of virtual network companies. These networks are driven by technology, as in the computer industry, or by geography, as in the airline industry. ${ }^{3}$ Such networks can even lead to new industries, as recent integration of the computer, telecom and entertainment industries has shown.

Forming and managing such complex, international, knowledge-intensive alliances places a great burden on the managers involved. Despite high hopes for realising synergies, many alliances do not deliver the value that the alliance partners had expected. As Pearce has remarked with respect to joint ventures, "The high rates of failure suggest that the problem may be generic to the governance form." 4

The core of the alliance issue lies in the potential conflict between cooperation and competition. Hamel, Doz and Prahalad are quite clear on this issue and propagate an opportunistic cooperation tactic. ${ }^{5}$ In their opinion, a company should try to outlearn its partner. It is true, in fact, that alliances, especially in technology-intensive industries, can lead to "learning races" which rapidly erode the very foundation of the alliance. ${ }^{1}$ The question is whether alliances must be regarded as modern Trojan horses leading inevitably to a win-lose situation.

On the basis of our research, we have concluded otherwise, provided that the managers involved are willing to take a different view. ${ }^{6}$ During negotiations, as well as during day-to-day running of the alliance, management must primarily focus on achieving and maintaining a good 'fit' between the partners. Also, managers must have a profound understanding of the dynamics of fit and manage this effectively.

In this article, we will first present the general fit framework that we have developed. Secondly, we will provide insight into the factors that actually determine strategic and organisational fit, and the way in which managers can determine whether there is, indeed, sufficient fit between the partners to enable successful cooperation. The framework is applied in its entirety to the Unilever/ToniLait case study. The other cases mentioned throughout this article will be used to illustrate specific elements 
of the framework. Finally, we will discuss the relationship between the aspects of fit identified, and we will provide practical recommendations as to how to manage the dynamics of fit. Our research methodology and the cases we studied are described in Appendix A.

\section{Striving for fit instead of for one-sided advantages}

Alliance success depends on an effective and efficient alignment (in other words, fit) between the partners involved. The concept of fit itself is not new. In the late 1960s, the contingency theory argued that the effectiveness of a specific type of organisation heavily depends on the environment in which it operates. ${ }^{8}$ Or, as Miles and Snow argue, when designing an organisation, management must put together a well-balanced package of strategy, structure, processes and a managerial ideology that holds these together. This is quite often referred to as internal fit. ${ }^{9}$ Here the alignment between one organisation and its environment is made central.

Within the context of mergers, acquisitions and alliances, the concept of fit was broadened by incorporating the alignment between companies. In 1991, Niederkofler distinguished between strategic and operating fit: ${ }^{10}$ a differentiation that has also been used by Jemison and Sitkin in their work on acquisition integration. ${ }^{11}$ Quite often parallels are drawn between alliances and mergers or acquisitions. Yet, there is a distinct difference: in any alliance, even in joint ventures in which an equity participation is involved, partners remain independent. In a merger or acquisition, however, control is not shared, because one integrated company is formed. The fact that alliance partners remain independent demands a different approach to alignment or integration. It is crucial to balance the interests and backgrounds of the partners involved, so that a win-win situation is created. Within the context of alliances, fit is very much related to concepts such as complementary balance, mutual benefits, harmony and dependency. We have, therefore, focused on the issue of collective alignment, instead of on the individual strategy formulation and organisational design of the partners. Based on our research, we have concluded that alliance success requires a good fit in five areas (see Figure 1). Here, alliance success is defined as the degree to which both partners achieve their alliance objectives.

It is crucial that alliance managers address all of these five aspects of fit in their mutual relationship: an insufficient fit in one area can lead to alliance failure. Human fit is indeed an essential lubricant for alliance processes, as Boersma also argues, ${ }^{12}$ and the issue of cultural fit has caused "many headaches" in corporate boardrooms (see Lewis, for example ${ }^{13}$ ). The impact of operational fit, which will normally be influenced by a large number of contingencies, should not be ignored either. However, discussing all aspects of fit in-depth does not fit within alliances demand a

different approach to

fit 


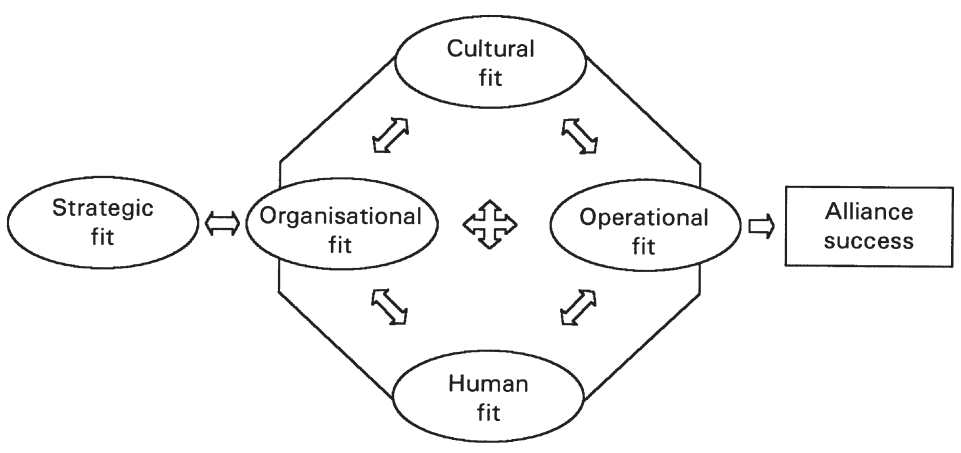

Figure 1. The generic fit framework

the scope of one article. So, without ignoring the impact the other aspects of fit may have, we have decided to focus in this article on the content aspects of alliances, in other words on strategic and organisational fit (as is also indicated in Figure 2).

\section{A dynamic perspective on strategic and organisational fit}

One could argue that the traditional concept of fit is too static considering the dynamic nature of strategic alliances. Indeed, every alliance is a repetitive sequence of stages of negotiation, commitment and execution in which the strategic objectives, organisational structures, operational activities and cultures, as well as the individual interests of the partners must be aligned. ${ }^{14}$ The fit that the partners have established will be continuously challenged by changes in the environment or within the organisation of one of the partners.

We therefore take a dynamic rather than static view of fit. A good fit may deteriorate over time, whereas an insufficient fit at the start of an alliance can sometimes be improved, provided the alliance partners have the capacity to manage the dynamics of fit effectively. This requires, firstly, that fit can potentially be improved, if it is limited at the start of the alliance, and secondly, that the partners know how to manage fit. So, within the context of the generic fit framework (Figure 1), this article focuses on strategic and organisational fit and the capacity to manage the dynamics of fit (Figure 2).

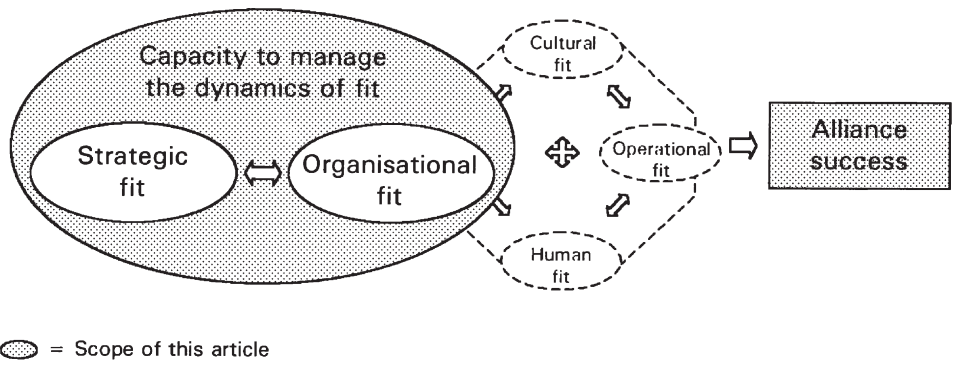

Figure 2. The scope of this article 
Managing fit effectively may require considerable investment, as is illustrated by the following case. Stork Werkspoor Diesel and Wärtsilä Diesel both produce medium speed diesel engines for ships and power plants. Both companies faced specific challenges. Stork Werkspoor Diesel had just escaped bankruptcy and lacked the financial resources to develop new engines. Wärtsilä Diesel had a dominant and profitable market share in its Scandinavian home market, but needed to expand internationally in order to sustain growth. Globalisation, service on a worldwide scale and huge investments in product innovation were deemed necessary to remain competitive. The strategic fit appeared to be good. Wärtsilä Diesel had the financial resources and technical expertise that Stork Werkspoor Diesel needed, whereas Stork had a strong international service network outside of Scandinavia.

Based on this analysis, the partners decided to form a joint venture to develop and produce medium speed diesel engines. However, despite the obvious fit in several aspects, the results proved to be very disappointing in the first year and a half. The poor results were caused by the partners' decision to maintain two engine portfolios, which contained considerable overlap. (The fit was actually quite limited in this aspect.) Potential synergies were not effected, and problems and mistrust arose within the sales organisation as well as at the board level (in other words, there was an insufficient human fit). In the context of a major reorientation, initiated by a newly appointed manager (which reduced mistrust), the companies decided to change the joint venture's strategy and to develop a complementary portfolio. As a result of this major investment, strategic fit was gradually strengthened, and, despite a bad start, both partners eventually considered the alliance to be successful.

\section{Strategic fit determines the alliance potential}

Developing a good strategic fit is a prerequisite for any alliance. Achieving strategic fit requires that individual interests are

\section{Exhibit 1. Drivers for strategic fit}

1. Do the alliance partners have a shared strategic vision on developments in the alliance environment?

2. Are the partners' alliance and corporate strategies compatible?

3. Is the alliance of strategic importance to both partners?

4. Are the partners mutually dependent for achieving their objectives (complementary balance)?

5. Do the joint activities have added value for the clients and the partners?

6. Will the alliance be accepted by the market (buyers, competitors, government)? there are six drives to

fit 
weighed against the anticipated advantages and potential risks of the alliance. On the one hand, this process must be carefully planned and managed. Yet on the other hand, the importance of intuition and entrepreneurship should not be underestimated. During discussions, partners must answer six questions to determine the degree of strategic fit (see Exhibit 1). Depending on the outcome, they must decide whether, and under what conditions, the alliance offers an interesting business opportunity.

\section{Understanding the drivers for strategic fit}

Firstly, cooperation is only advisable when partners have a shared vision of the future developments within the industry in which the alliance will be formed, and of the impact that these developments will have on their individual positions. This shared vision

successful alliances

add value to partners

and their customers will enable the partners to resolve strategic issues effectively, particularly in the later stages of the alliance, when partners often have to redefine their initial premises and objectives due to changes in their environment. The second precondition for strategic fit is compatibility of strategies. ${ }^{15}$ Potential partners must be aware that compatible alliance strategies do not necessarily correspond to compatible corporate strategies. After all, the partners remain competitors in many other areas. Managing this dual competitive dimension is one of the key challenges that alliance partners face and may require concessions from both sides.

The alliance partners will only be prepared to make these concessions when the alliance is of strategic importance to them, ${ }^{16}$ which is the third driver for strategic fit. The need to cooperate is determined by pressure on continuity, market opportunities, time pressure or the number of alternative options (such as autonomous development or acquisitions). However, a shared vision, compatibility of strategies and the strategic importance of cooperation do not sufficiently explain why companies ultimately form and maintain an alliance.

A successful alliance also requires mutual dependency. This is the fourth factor determining strategic fit. In general, it may be stated that the better the partners complement one another (with respect to know-how, markets, resources and so on), the better the chances are that the alliance will be successful. Sustaining mutual dependency requires a proactive attitude from the managers involved. They must try to avoid, for example, unwanted transfer of knowledge (see the DSM/GB case study in this respect) or too great an overlap in markets, which would reduce mutual dependency.

Quite often, alliances are contemplated which are less advisable than enthusiastic entrepreneurs would have us believe. In the heat of negotiations, cooperation sometimes becomes a goal in itself in order to boost the status of the board. This should be avoided at all costs. Any alliance should have added value for the partners and/or their customers. In addition to this, partners must carefully consider whether the market will accept the alliance; this is the last driver for strategic fit that we have identified. Alliances quite often change the competitive balance within 
the industry. Whenever possible, negative reactions or countermeasures from suppliers, customers or competitors should be anticipated well in advance. In this context, compliance with anti-trust legislation is an additional issue, especially for major alliances.

\section{Be aware of the dynamics of strategic fit}

Based on these six drivers, partners can determine the degree of strategic fit. Basically, three situations can arise. The first is where there is a good strategic fit between the partners. In this case, a good basis for cooperation exists. Secondly, there may be a limited fit. Here, the partners must carefully consider whether the degree of strategic fit can be strengthened, and otherwise should decide not to cooperate. Thirdly, a combination of the aforementioned two may occur (in other words, a mixed fit). In Figure 3 these situations are illustrated by examples from our research.

So even when strategic fit is limited or mixed, partners may decide to cooperate. This decision will, however, place greater demands on the design of the alliance and the implementation process, as the SmitWijs joint venture shows. Smit International and Wijsmuller are the world's number one and number two, respectively, in the salvage and sea towage market. There was cut-throat competition between these two companies for decades. When both Smit and Wijsmuller appointed new managing directors, their relationship improved. For the first time in years, the top management of both companies started to trust each other. In sea towage, to service clients efficiently, flexibility and worldwide coverage are essential. In their industry, margins were under considerable pressure at that time. The new managing directors concluded that combining forces could offer substantial benefits, but they also knew that, considering their competitive history, a successful cooperation would require a careful approach. The negotiations between Smit and Wijsmuller focused on their sea towage activities. Their highly profitable salvage businesses, which each company considered to be its core business, were excluded from the alliance negotiations. The successful fit requires

flexibility and

adjustment overtime

Degree of strategic fit at the start of the alliance

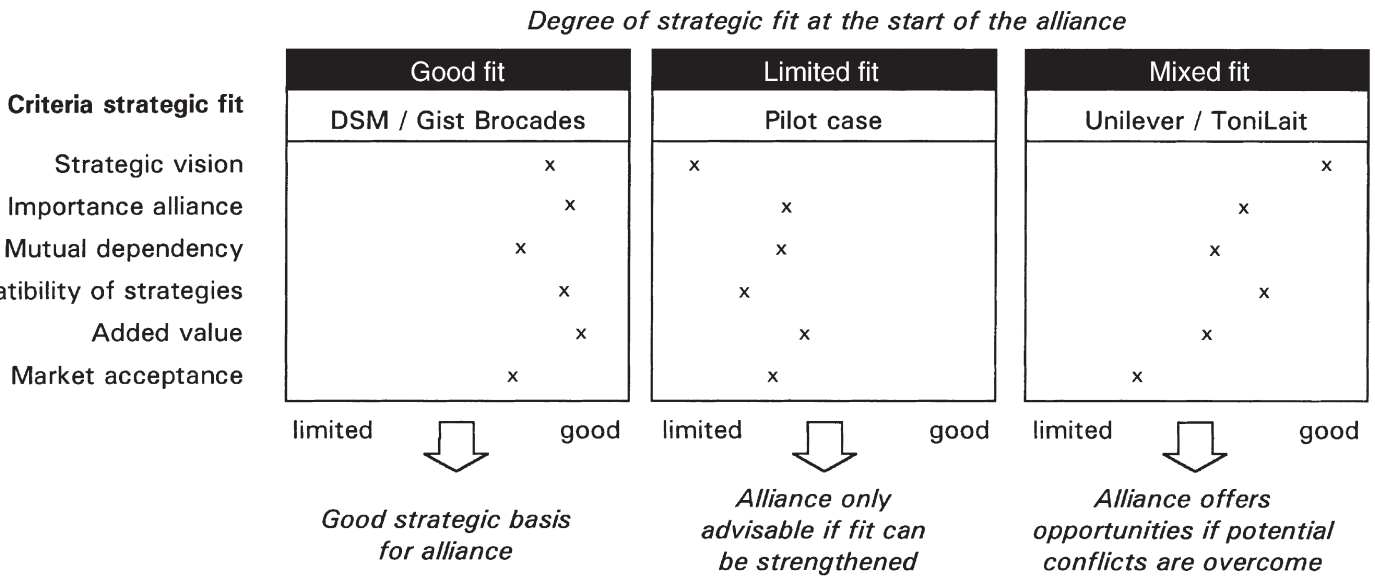

Figure 3. Good, limited and mixed strategic fit 
alliance objectives were quite compatible: cost reduction and expansion of geographical scope.

To achieve these objectives, the SmitWijs joint venture was formed to coordinate their joint towage business. Salvage jobs were not handled by the joint venture, but divided between the partners using a transparent set of rules. In this way, potential conflicts were avoided. The joint venture organisation consisted of two managers and an assistant. Quite often, alliance partners tend to divide management positions equally. Smit and Wijsmuller, however, appointed two Smit managers, because they were considered to be the most competent. Having two Smit managers at the helm required a great deal of trust between the companies. Besides illustrating the important role of trust in alliance negotiations and design, this case also shows that an insufficient strategic fit in certain areas (that is, a mixed fit) can be resolved by the right alliance design and agreements.

\section{Organisational fit determines alliance feasibility}

In almost every case that we have investigated, the alliance managers indicated that the organisational fit was a critical success factor. Based on our research, six drivers for organisational fit have been identified. These are shown in Exhibit 2.Organisational fit is not the same as organisational equality. Alliance partners will almost always differ in terms of market position, organisational structure, management style and corporate values. Explicating these differences is of crucial importance in arriving at a profound understanding of the partners. The first and main challenge when designing the alliance is to address organisational differences in such a way that effective cooperation is facilitated. A dynamic view on fit is essential here. As Doz has remarked, "It is a dynamic relationship: adjustment and flexibility have to be part of most partnerships." ${ }^{\prime 6}$ Changes in the environment or

\section{Exhibit 2. Drivers for organisational fit}

1. Are organisational similarities and differences addressed in the alliance design?

2. Does the alliance design provide strategic and organisational flexibility?

3. Has the complexity of the alliance design been reduced as far as possible?

4. Does the alliance design enable effective management control for both partners?

5. Are potential strategic conflicts overcome by the alliance design?

6. Does the alliance design enable the partners to achieve their strategic objectives? 
within the organisation of one of the partners may challenge initial premises and may force partners to redefine their alliance objectives or design. The alliance must, therefore, provide strategic and organisational flexibility, the second driver for organisational fit. This second driver closely relates to the third, the complexity of the alliance design. Complex alliances will, in general, face more difficulties in adapting to new developments. Killing notes in this respect, "An alliance must be simple enough to be manageable." 17 Manageability may be accomplished by limiting the scope of the alliance, reducing the number of partners, or introducing a clear division of tasks. Strictly speaking, the alliance should focus on those activities where collaboration has added value to both partners.

In their quest for control, alliance partners occasionally tend to select a more intensive alliance design than is necessary. Alliance negotiations frequently flounder because of the power issue: who has ultimate control of the business? Yet it is a moot point whether one of the partners should have full control. Organisational fit requires that the alliance design enables effective management control for both partners, the fourth driver. Control is not solely concerned with formal authority and equity shares; it also concerns the way in which authority is exercised, and the way in which decisions are made. The Unilever management that we interviewed made an interesting comment in this respect: "at the end of the day, financial participation is irrelevant; its all about management control and trust." Management control was defined here as "running the business according to your own principles and controlling decision making points crucial to the success of the business."

When evaluating strategic fit, partners should identify potential strategic conflicts. Think, for example, of Smit and Wijsmuller, who remained competitors in their salvage operations. Unresolved conflicts may threaten the success of the alliance in the long run. As the fifth driver states, partners must, therefore, address potential strategic conflicts in the alliance design to ensure long-term stability. The sixth driver for organisational fit closely relates to strategic fit. In the heat of negotiations, concessions are often made, or partners lose sight of their initial objectives. Therefore, before signing a deal, we recommend that alliance partners, once again, carefully test whether the chosen design ultimately enables them to achieve their strategic objectives.

\section{Evaluating strategic and organisational fit}

The drivers for strategic and organisational fit that we have discussed in the previous two sections will enable managers to evaluate the degree of fit with their potential partner, and thus the feasibility of their alliance. This premise immediately raises two questions: how can fit be measured, and what degree of fit is required for a successful alliance? This section addresses the first question, which is illustrated using the Unilever/ToniLait case. The second question is discussed separately. alliance feasibility can

be measured 
partners should

evaluate their

absolute scores and

their differences
For each of the drivers that we have identified, each of the potential partners must individually judge to what extent they can affirmatively answer the questions listed in Exhibits 1 and 2. Several of these drivers can be broken down into "sub-factors". As discussed earlier, for example, the strategic importance of the alliance (the third driver for strategic fit) is determined by pressure on continuity, market opportunities, time pressure and the number of alternative options. For drivers that contain sub-factors, a more detailed analysis must be performed, addressing all of the sub-factors. In general, the input for this analysis is the vision of top management, business plans, market trend analysis, competitor analysis, data on organisational structure, and financial performance. Basically, this analysis is about doing the necessary homework. At the end of the day, however, the key to any alliance is in the hands of the managers involved in the negotiations, for which our framework may set the agenda. The results of these discussions can be plotted on a chart, similar to the one shown in Figure 3. We have chosen to "measure" fit in qualitative terms of good, mixed or limited fit. This will not automatically lead to unambiguous insights into whether or not the partners should cooperate, unless most elements have very low scores. (In that case, the partners should obviously refrain from going through with the cooperation.)

If we take strategic importance as an example again, it might be that the continuity of one of the partners, A, is under considerable pressure and that it has no options left, other than forming an alliance. If this is not the case for A's potential partner, $\mathrm{B}$, there is a considerable difference in strategic interest between the partners. In this situation, the managers involved should explicitly discuss two important issues. Firstly, is B as committed to the alliance as A? Or, to put it differently, is A willing to accept the risk that $B$ might not put as much effort into the alliance as A? Secondly, if the companies still wish to cooperate (because there is a strategic fit in other areas or drivers, for example), how will the difference in strategic interest influence the division of management control? Will A indeed have more influence on the alliance, or do the partners consider trust to be a sufficient coordinating mechanism?

So, in summary, strategic fit is about evaluating the absolute scores (good, mixed or limited) and the relative differences between the partners. This evaluation will enable the partners to identify, and discuss, potential strategic conflicts. Subsequently, the outcome of this evaluation and any ensuing discussions must be translated into the alliance design.

It should be noted that our framework does not provide a clear-cut recipe for instant alliance success. By using the analytical framework presented here, alliance managers will be able to better structure, explicate and focus their alliance talks. One might prefer to quantify the degree of fit between alliance partners. Quantifying fit is certainly an interesting area for further research, which would have to be of a different nature from our research (hypothesis testing). Yet, at the end of the day, the final 
go/no go decision will always come from a combination of indepth analysis and explicit discussions structured by our framework, and the business sense and the entrepreneurship of the partners involved.

The method of evaluating strategic and organisational fit discussed above is mainly derived from the experience that we gained from our in-depth case studies. As discussed in Appendix 1 , our framework has been consistently applied in all of these cases. To further illustrate how management can actually use our framework in practice, one of the cases, Unilever/ToniLait, will be discussed in greater detail. The reason for focusing on this particular case is twofold. Firstly, not all cases can be discussed in-depth within the scope of this article. Secondly, because the Unilever/ToniLait case was the last one that we studied for our developmental research (to obtain an initial indication of external validity), it covers our final framework most closely.

\section{The case of Unilever and ToniLait}

Unilever is the world leader in the ice cream market. ToniLait is a merger of five farmers' cooperatives ("Milchverbände"). Together, these two companies control around 50 per cent of the Swiss dairy market. Although ToniLait considers ice cream to be a non-core product, ice cream sales contribute substantially to the company's profits. In 1995, Unilever and ToniLait decided to form a joint venture in the marketing, sales and distribution of ice cream in Switzerland. The joint venture was called Pierrot-Lusso.

At first glance, it seemed that the partners needed to bridge a substantial gap, both in terms of their strategic backgrounds and their business paradigms. Partly for this reason, the strategic fit between them was mixed: a good fit on some drivers, but not on others. This mixed strategic fit is explained in Table 1.

The main challenge now was to design an alliance that would address the potential conflicts resulting from a mixed strategic fit, and one that would enable the partners to manage their organisational and cultural differences. The alliance design is summarised in Figure 4. During the process of designing the alliance, several times the negotiations almost ended prematurely because some issues threatened to prove irresolvable by the partners. The commitment of both boards, the thorough preparation and the belief in consensus were decisive in realising a good organisational fit (see Table 2).

This case illustrates that even when there is a mixed strategic fit, the alliance can be successful, provided that the alliance partners address this adequately in the alliance design and realise a good organisational fit. By carefully analysing the drivers for fit, the actual strategic basis for the alliance and its organisational feasibility can be fully understood. Such insights are vital in any alliance process. the challenge was to

design an alliance

that would address

conflicts 


\begin{tabular}{|c|c|c|}
\hline Driver & Evaluation of the Unilever/ToniLait alliance & Strategic fit \\
\hline $\begin{array}{l}\text { Shared strategic } \\
\text { vision }\end{array}$ & $\begin{array}{l}\text { The starting point for cooperation lay in the shared vision that both } \\
\text { partners had of the Swiss ice cream market. The main trends were } \\
\text { overcapacity in local production, a shift to international brands (like } \\
\text { Unilever's Magnum), pressure on the cost price and concentration } \\
\text { among retailers. Agreement on these trends and their impact was } \\
\text { reached at an early stage. }\end{array}$ & Good \\
\hline $\begin{array}{l}\text { Importance of } \\
\text { the alliance }\end{array}$ & $\begin{array}{l}\text { An internal analysis had shown that, considering these trends, ToniLait } \\
\text { would need an international partner in order to survive in the ice } \\
\text { cream market. For Unilever, the alliance was important as well, albeit } \\
\text { for offensive reasons: ice cream was a core activity and Unilever strived } \\
\text { for the no. } 1 \text { position in every country. In Switzerland, obtaining this } \\
\text { position was hindered, however, by high import duties on ice cream, } \\
\text { concentration among retailers, and Nestlé's home advantage. }\end{array}$ & $\begin{array}{l}\text { ToniLait: good; } \\
\text { Unilever: medium }\end{array}$ \\
\hline $\begin{array}{l}\text { Dependency of } \\
\text { the partners }\end{array}$ & $\begin{array}{l}\text { Unilever needed ToniLait's distribution network and production } \\
\text { capacity for its global brands ("the hardware"), whereas ToniLait } \\
\text { needed Unilever's brands and production know-how ("the software"). } \\
\text { This complementary balance proved to be a major strength for their } \\
\text { alliance. }\end{array}$ & $\begin{array}{l}\text { ToniLait: good; } \\
\text { Unilever: medium }\end{array}$ \\
\hline $\begin{array}{l}\text { Compatibility } \\
\text { strategies }\end{array}$ & $\begin{array}{l}\text { The partners' objectives where reconcilable to a large degree. Strategic } \\
\text { fit was also good at the level of their corporate strategies. Unilever was } \\
\text { a far more attractive partner for ToniLait than Nestlé, which sees dairy } \\
\text { as a core activity (Unilever does not). Vice versa, ice cream was a non- } \\
\text { core activity for ToniLait, which reduced potential conflicts with } \\
\text { Unilever. }\end{array}$ & Medium/good \\
\hline Added value & $\begin{array}{l}\text { The alliance was primarily formed to realise economies of scale and } \\
\text { scope. Cooperation was advantageous for Pierrot-Friola retailers, in } \\
\text { that they too have international Unilever brands at their disposal. } \\
\text { Additionally, the more efficient distribution infrastructure would } \\
\text { improve service and delivery time. }\end{array}$ & Medium \\
\hline $\begin{array}{l}\text { Market } \\
\text { acceptance }\end{array}$ & $\begin{array}{l}\text { An important element of the alliance was the integration of marketing } \\
\text { and distribution activities. This implied a rationalisation of their } \\
\text { existing wholesaler network. However, these wholesalers might combine } \\
\text { forces, if their contracts were abruptly terminated. During the alliance } \\
\text { preparation, substantial effort was made to manage this risk. }\end{array}$ & Limited/medium \\
\hline
\end{tabular}

\section{Manage fit to exploit the alliance potential}

The second question raised regarding our framework was what degree of fit is needed to enable successful cooperation, and how should partners manage fit over time? The challenge of alliance management was also recognised by Hamel, who stated: "Making a collaborative agreement work has generally been seen as creating the preconditions for value creation. However, little advice is given on how to reap the benefits of being a good partner." 19 The cases that we studied clearly demonstrated that, once the alliance is formed, achieving and maintaining a good fit over time is perhaps one of the most difficult challenges that alliance partners face. The results of these case studies are summarised in Figure 5. 


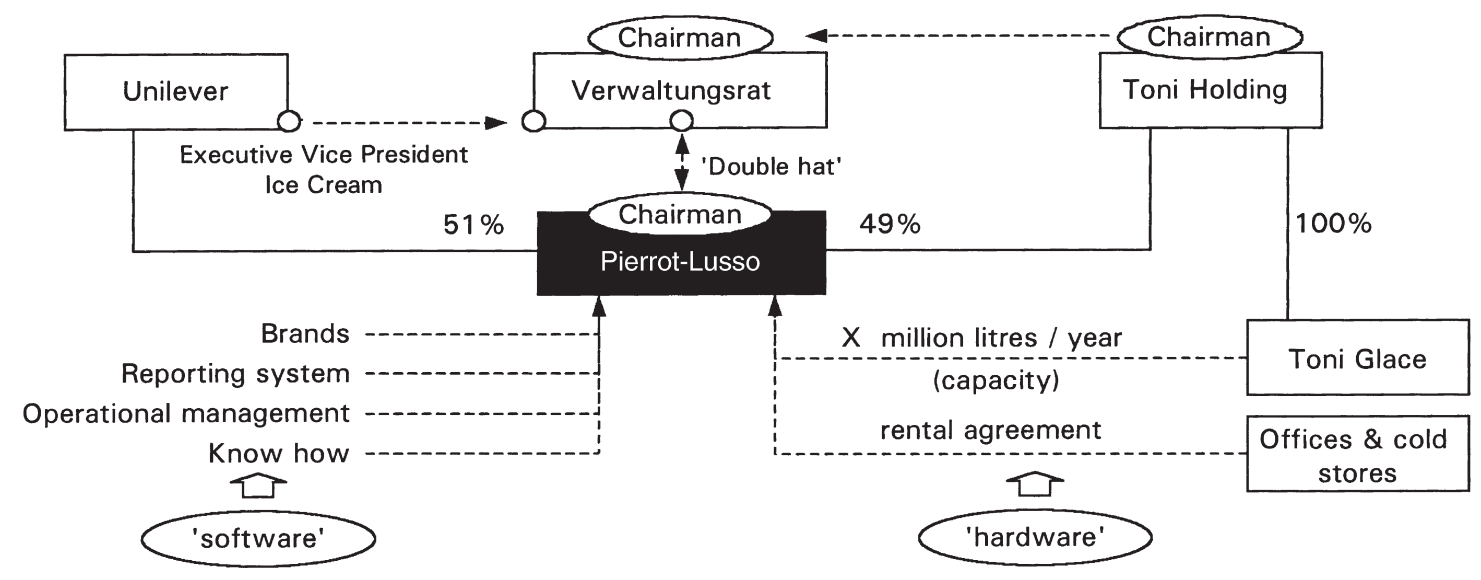

Figure 4. Design of the Unilever/ToniLait alliance

It is obvious that potential partners must always refrain from forming an alliance when fit is limited and there is no prospect of improvement. Yet, on the other hand, a limited fit at the start of the alliance does not necessarily imply that the partners should refrain from cooperation. Stork and Wärtsilä experienced a limited fit and an unsuccessful start, which they improved upon by redefining the alliance strategy. Both the SmitWijs alliance and the Unilever/ToniLait alliance had to deal with a mixed fit, which they addressed effectively in the alliance design, whereas the DSM/GB alliance (see below) had to exert great effort to sustain over the long run the good fit that they started out with.

Without deliberate management action, even a strategic alliance with great potential (a good fit) can have disappointing results, or turn into an unwarranted learning race. In the first section of this article, we raised the issue of whether strategic alliances should be regarded as modern Trojan horses. Especially in today's alliances, complementary know-how is essential. Once the alliance has been formed, however, the complementary balance between partners may shift due to either deliberate or unintentional knowledge transfer. Then, the ability to learn is crucial. This ability is determined by what Lane and Lubatkin describe as "relative absorptive capacity". ${ }^{18}$ Absorptive capacity is defined as the ability to recognise the value of external knowledge, assimilate it and apply it to a commercial end. Partners with a similar dominant logic and organisational structure are better positioned for knowledge transfer. Tacit knowledge, which often determines the competitive edge of the company, is more difficult to transfer and requires interactive learning between the two firms.

The alliance between the chemical companies DSM and Gist Brocades is a good example of how partners can benefit from complementary know-how, without eroding the actual basis for fit. For both DSM and Gist Brocades (GB), ${ }^{a}$ the technology available played an important role in the search for a partner. Both companies produce intermediates for antibiotics. Their core technologies, however, are totally different (fine chemistry for DSM and fermentation for GB). The primary objective of their

a DSM recently acquired Gist Brocades, but this was not a consequence of this joint venture. 


\begin{tabular}{|c|c|c|}
\hline Driver & Evaluation of the Unilever/ToniLait alliance & Organisational fit \\
\hline $\begin{array}{l}\text { Differences } \\
\text { addressed }\end{array}$ & $\begin{array}{l}\text { Pierrot-Friola and Lusso-Eldorado clearly had a different business } \\
\text { paradigm. If their marketing, sales and distribution organisations had } \\
\text { continued to exist alongside each other, the differences would have } \\
\text { remained, with all the problems of alignment. Integrating both } \\
\text { organisations was certainly tricky, but, as it turned out, it enabled the } \\
\text { active management of differences. }\end{array}$ & Good \\
\hline $\begin{array}{l}\text { Alliance } \\
\text { flexibility }\end{array}$ & $\begin{array}{l}\text { As a part of the joint venture agreement, long-term delivery contracts } \\
\text { were closed, which ensured capacity utilisation for ToniLait. Such long- } \\
\text { term arrangements, however, reduce alliance flexibility. }\end{array}$ & Medium \\
\hline $\begin{array}{l}\text { Alliance } \\
\text { complexity }\end{array}$ & $\begin{array}{l}\text { By restricting the alliance to marketing, sales and distribution and } \\
\text { excluding production, the complexity of the alliance was reduced. } \\
\text { Furthermore, the input from both partners was highly complementary } \\
\text { which also reduced the complexity of the alliance. }\end{array}$ & Good \\
\hline $\begin{array}{l}\text { Effective } \\
\text { management } \\
\text { control }\end{array}$ & $\begin{array}{l}\text { The power issue was a very delicate one, in the light of ToniLait's } \\
\text { initial fear of a gradual takeover by Unilever. Unilever "supplied" the } \\
\text { general manager of the joint venture. Yet, to balance this, ToniLait's } \\
\text { chairman was appointed as chairman of the "Verwaltungsrat" } \\
\text { (Supervisory Board), which has substantial influence within Swiss } \\
\text { corporations. In addition to this, ToniLait retained full control over its } \\
\text { own production facilities. This control structure adequately reflected the } \\
\text { strategic interest that the alliance represented for each partner. }\end{array}$ & Good \\
\hline $\begin{array}{l}\text { Strategic } \\
\text { conflicts }\end{array}$ & $\begin{array}{l}\text { Due to the mixed strategic fit, Unilever and ToniLait faced a few } \\
\text { potential strategic conflicts. The main areas for concern were the long- } \\
\text { term sustainability of the strategic fit, Unilever's potential dominance } \\
\text { and the wholesaler issue. By clearly defining the complementary inputs } \\
\text { and the balance in management control, Unilever and ToniLait were } \\
\text { able to effectively address these issues in the alliance design. }\end{array}$ & Good \\
\hline $\begin{array}{l}\text { Realisation of } \\
\text { objectives }\end{array}$ & $\begin{array}{l}\text { The objectives of the partners were realised to a substantial degree in } \\
\text { the first year. Unilever secured local ice cream production, so that } \\
\text { import duties were avoided. In addition, the brand position was } \\
\text { doubled by the joint venture. Through the joint venture, ToniLait was } \\
\text { able to guarantee full use of its production capacity, and gained access } \\
\text { to strategically essential international brands. }\end{array}$ & Good \\
\hline
\end{tabular}

Chemferm joint venture was to exploit this combined potential. Both partners were well aware that their alliance entailed a major, and also classical, risk: erosion of their competitive advantage through knowledge transfer. Within the scope of the alliance, both partners were deemed able to incorporate the know-how of the other within five years.

Eventually, the partners decided not to integrate both Research and Development departments. Projects were executed at one location, but by a mixed team consisting of both GB and DSM engineers. The project leaders reported to their own Research and Development manager with regard to resources, and to the Chemferm technology manager with regard to budgets and results. In principle, Chemferm was involved as little as possible in the day-to-day management of the projects. Chemferm's role 


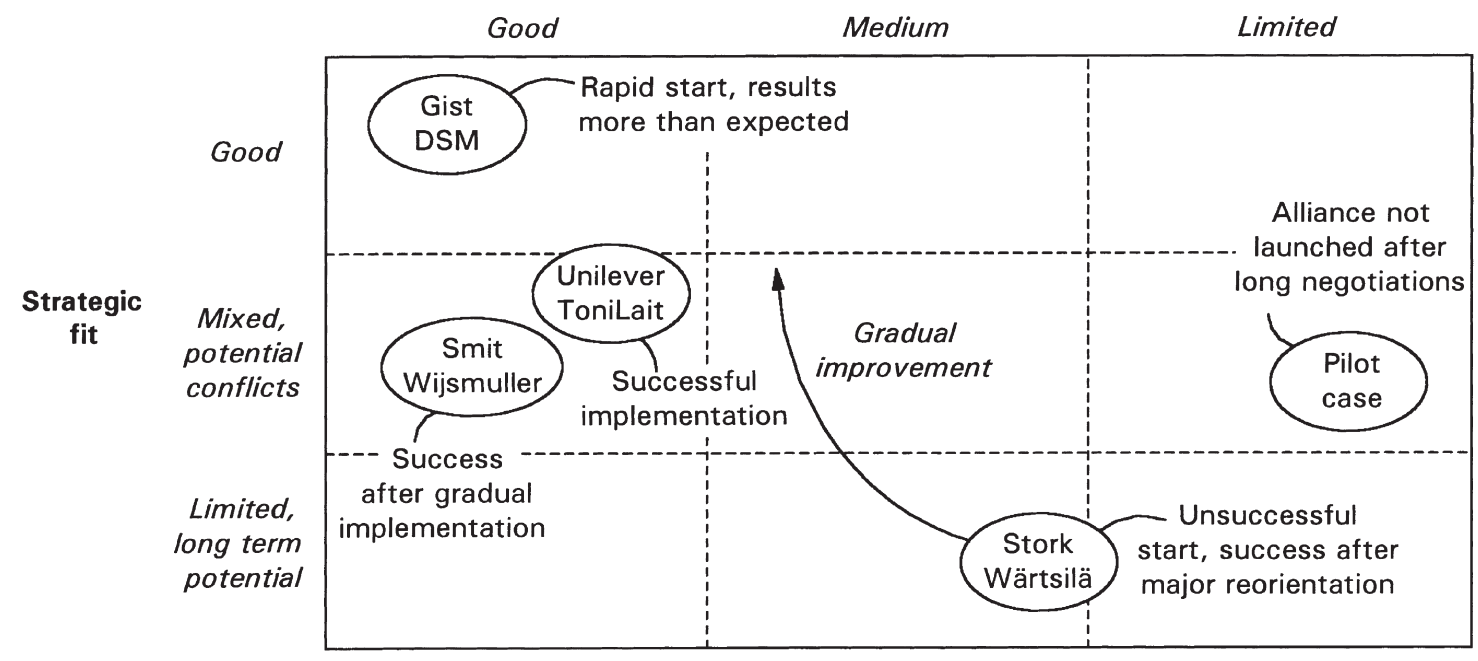

Figure 5. Case study results

was primarily initiating and facilitating, with an emphasis on "synergy finding". Chemferm sometimes deliberately stimulated internal competition between DSM and GB. Chemferm's basic philosophy is that both partners should strengthen their respective core technologies through the joint venture. By managing this balance very carefully, Chemferm enabled GB to improve in the fermentation area and DSM to improve in the fine chemistry area. In doing so, GB, DSM and Chemferm created a win-winwin situation and strengthened, rather than eroded, the degree of fit.

Fit is a prerequisite for alliance success, as we argued in the previous sections. At the end of the day, however, it is the partners' capacity to manage the dynamics of fit over time that will make the difference between alliance success or failure. Our research indicates that this capacity to manage fit is determined by four factors.

First of all, management must be able to identify those areas where fit is limited or where it may erode over time. This can be done by analysing and explicitly discussing the drivers for strategic and organisational fit we have presented in this article. When fit is limited or mixed, there is quite often a strong reason for the alliance partners to do something about it. Think for example of the Stork/Wärtsilä case we discussed. However, when strategic and organisational fit are good at the start of the alliance, the partners must be aware that management attention should not directly shift to other, more urgent matters. The fit between DSM and GB was very good at the start, yet, without the conscious efforts of the boards and alliance managers involved, this good fit could have disappeared rather quickly.

Managing fit, secondly, requires an "alliance attitude". Effective alliance managers focus on creating win-win situations, adopt a collaborative attitude and develop relationships based on 
four factors determine

whether fit will

improve trust. This is an attitude which managers, who are well-trained in competitive behaviour, do not necessarily adopt, yet which should be deeply embedded in the partners' cultures. Top management must be aware that it is a role model for the rest of the organisation. The CEO's of Smit and Wijsmuller (who were cutthroat competitors for decades) were well aware of this, and were quite successful in changing the mindset of their middle managers. This did require several years though, which illustrates once again that building an organisation that is capable of managing alliances cannot be done overnight.

Alliance managers should not only focus on managing the alliance itself, but also invest substantially in the development of the alliance management capabilities of their own organisation. Alliance management capabilities are the third factor determining the capacity to manage fit. Spekman et al. have remarked in this context: "It is unwise to place key alliances in the hands of the inexperienced." ${ }^{20}$ Successful alliance partners can balance the interests of their partners with their own, maximise the potential of their network of partners, are capable of understanding and managing cultural differences, and know how to walk the fine line between competition and collaboration. Recent research indicates that the conscious development of alliance capabilities helps managers to leverage their previous alliance experience. Effective development of alliance capability can be achieved through a joint evaluation of alliance results, the assignment of alliance specialists at the level of middle management, or even at the operational level, and the training of managers involved in alliances. ${ }^{21}$

Managing fit effectively requires, fourthly, that partners set clear and ambitious performance targets for their alliance and regularly compare the alliance results with their initial objectives and targets. Besides analysing the alliance's financial performance (an obvious performance indicator), we would urge alliance managers to also evaluate the degree of fit during such a performance review. Based on the results of this review, management can assess whether or not the fit it initially established has eroded over time.

\section{Conclusions}

In this article, we have presented a framework for strategic and organisational fit. This framework is based on in-depth case study research into strategic alliances. A criticism often made of case study research concerns its external validity. The research results (the drivers for strategic and organisational fit) are usually easily deducible from the specific cases, but cannot necessarily be generalised to a wider domain than the cases researched. We have addressed this inherent limitation by structuring our empirical research in three phases (the pilot case, three developmental cases and one final "test" case), each with a specific objective. An interesting area for further research is to test the hypotheses that can be derived from our framework. 
The main conclusions of our research are twofold. First of all, we argued that a good fit between the partners involved is crucial for attaining a successful alliance. With the fit framework presented here, alliance managers can gain insight into the drivers for fit and their potential impact on the success of the alliance. Partners must be well aware of the fact that an insufficient fit in any one area will have a significant negative impact on the alliance process. A limited or mixed fit, however, does not necessarily imply that the partners should refrain from cooperation, provided that the degree of fit can be strengthened and management is willing to invest substantially in doing so.

Our second conclusion is that even high-potential alliances may be unsuccessful if the alliance partners do not have the capacity to manage the dynamics of fit over time. This requires that the partners develop effective alliance management capabilities and develop an operating style and culture which is receptive to alliances. They must aim for a win-win situation and carefully manage the delicate balance between competition and cooperation. Perhaps the fastest route to alliance failure is to assume that the initial premises and objectives will not change over time. Frequent evaluation of the degree of fit is therefore essential if partners want to be able to manage fit. As is illustrated by the cases that we studied, fit is a dynamic concept and should be managed proactively. In the end, these two factors could make the difference between fit and failure!

\section{Appendix A. Research methodology and cases studied}

The insights presented here are based on Ph.D. research into strategic alliances. ${ }^{6}$ The objective was to develop a generic framework that could structure and focus the process of forming and managing strategic alliances. This framework has been developed in four phases, using an exploratory case study approach (see also Yin $\left.^{7}\right)$.

1. Based on an extensive literature review, we have chosen the concept of fit as the basis for our framework (see Figure 1). We then elected to focus on strategic and organisational fit in particular. The first phase resulted in a theoretical framework that not only identified the different aspects of fit and their interrelationships, but also identified the drivers for fit. Our initial theoretical framework consisted of three drivers for strategic fit (strategic importance, compatibility of strategies and mutual dependency) and three drivers for organisational fit (complexity, control and flexibility). The first phase was concluded by verifying the underlying assumptions of our framework with experts in the field of strategic alliances (both academic and practising). The main objective of the subsequent, retrospective case studies was not to test the hypotheses underlying our framework, but to further develop the framework. In keeping with this developmental objective, we
The authors would like to thank John Bell for his many comments on previous versions of this article. 
decided to study a limited number of cases in-depth. The cases that we studied were selected from a database that we developed containing over 150 alliances, derived from public sources. Our selection of cases from this database aimed at providing a balanced set of relevant cases consisting of, among other things, different industries, different objectives, and both successes and failures. Sixteen alliances were considered to be interesting. Eventually, five cases were chosen because of their relevancy to our research and because the companies were willing to participate. These cases are summarised in Figure 6.

2. Before entering into the main part of the field research, a pilot case was conducted (anonymously) to obtain an initial indication of the accuracy and comprehensiveness of our framework. Based on the pilot case, we concluded that most elements of our theoretical framework were relevant. However, it also became apparent that our initial drivers for organisational fit did not sufficiently explain the eventual failure of the alliance process in this case. Based on the pilot case, we therefore expanded our initial theoretical framework by adding three more drivers for organisational fit: the extent to which differences are addressed, the realisation of strategic objectives and the resolution of strategic conflicts.

3. We then researched three cases in parallel. The time frame we studied ranged from 1 to 5 years (see Figure 6). In all of these case studies, we used our framework to structure our analysis to see whether the drivers for fit that we had identified could adequately explain the strategic choices of the alliance partners and the resulting alliance process. Here, we focused on illustrating the relevance of the drivers that we had developed, identifying new drivers for strategic and organisational fit (and the underlying criteria), and gaining insight into the interrelationships between these drivers. The results of the case studies were intensively discussed with the participating managers and were integrated into the final framework. This led to three additional drivers for strategic fit (shared vision, added value and market acceptance) and a further refinement of the ones we already had.

\begin{tabular}{|c|c|c|c|c|c|c|c|c|c|}
\hline & Case & Industry & & & & Key activities & & The outcome & Successful \\
\hline Pilot case & Anonymous & Leisure & & & $x$ & $\begin{array}{l}\text { Joint sourcing and expansion of } \\
\text { of joint outlets }\end{array}$ & 1 & $\begin{array}{l}\text { Despite the strategic potential } \\
\text { the alliance was not launched }\end{array}$ & No \\
\hline \multirow{3}{*}{$\begin{array}{l}\text { Develop- } \\
\text { mental } \\
\text { cases }\end{array}$} & $\begin{array}{l}\text { Smit \& } \\
\text { Wijsmuller }\end{array}$ & Transport & & $x$ & $x$ & Sea towage with joint fleet & 3 & $\begin{array}{l}\text { Potential conflicts have been } \\
\text { overcome by the alliance design }\end{array}$ & Yes \\
\hline & $\begin{array}{l}\text { DSM \& } \\
\text { Gist Brocades }\end{array}$ & Pharma & $x$ & & $x$ & $\begin{array}{l}\text { Production and sales of } \\
\text { intermediates for antibiotics }\end{array}$ & 2 & $\begin{array}{l}\text { Due to a good fit, the alliance } \\
\text { was successful from the start }\end{array}$ & Yes \\
\hline & $\begin{array}{l}\text { Stork \& } \\
\text { Wärtsilä }\end{array}$ & $\begin{array}{l}\text { Diesel } \\
\text { engines }\end{array}$ & $x$ & $x$ & $x$ & $\begin{array}{l}\text { Development, production and sales } \\
\text { of medium speed diesel engines }\end{array}$ & 5 & $\begin{array}{l}\text { Initially, the alliance was not } \\
\text { successful due to a limited fit }\end{array}$ & $\begin{array}{l}\text { Yes, but } \\
\text { bad start }\end{array}$ \\
\hline $\begin{array}{l}\text { Final 'test' } \\
\text { case }\end{array}$ & $\begin{array}{l}\text { Unilever \& } \\
\text { Tonilait }\end{array}$ & Food & & $x$ & $x$ & $\begin{array}{l}\text { Production, marketing and sales } \\
\text { of ice cream for the Swiss market }\end{array}$ & 2 & $\begin{array}{l}\text { The alliance was successful due } \\
\text { to a good (organisational) fit }\end{array}$ & Yes \\
\hline
\end{tabular}

Figure 6. The research methodology and cases researched 
4. We then conducted a fifth case study, to which we applied the framework that resulted from phases 2 and 3. The main objective of this case was to obtain an initial indication of external validity. This final case study did not lead to further adjustments to our framework, and confirmed the relevance of the drivers that we had added based on the first four case studies. We therefore concluded that our framework seemed valid outside of the original research population.

\section{References}

1. G. Hamel, Competition for competence and inter-partner learning within international strategic alliances Strategic Management Journal 12, 83-103.

2. J. Hagedoorn and B. Sadowski, The transition from strategic technology alliances to mergers and acquisitions Journal of Management Studies 36, 87-107.

3. G. Lorenzoni and C. Baden-Fuller, Creating a strategic center to manage a web of partners California Management Review 37(3), 146-163.

4. R. J. Pearce, Toward understanding joint venture performance and survival Academy of Management Review 22, 203-225.

5. G. Hamel, Y. L. Doz and C. K. Prahalad, Collaborate with your competitor-and win, Harvard Business Review January-February, 133-139 (1989).

6. M. U. Douma, Strategic Alliances; Fit or Failure, Ph.D. thesis, University of Twente (1997).

7. R. K. Yin, Case Study Research, Design and Methods, Sage, Newbury Park, CA (1998).

8. P. R. Lawrence and J. W. Lorsch, Organisation and Environment: Managing Integration and Differentiation, Harvard University Press, Boston, MA (1967).

9. R. E. Miles and C. C. Snow, Fit Failure, and the Hall of Fame: How Companies Succeed and Fail, The Free Press, New York (1994).

10. M. Niederkofler, The evolution of strategic alliances: opportunities for managerial influence Journal of Business Venturing 6(July), 237-257.

11. D. B. Jemison and S. B. Sitkin, Corporate acquisitions: a process perspective Academy of Management Review 11, 145163.

12. M. F. Boersma, Developing trust in international joint ventures, Ph.D. thesis, University of Groningen (1999).

13. J. D. Lewis, Partnerships for Profit; Structuring and Managing Strategic Alliances, The Free Press, New York (1990).

14. P. S. Ring and A. H. van de Ven, Developmental processes in cooperative inter-organisational relationships Academy of Management Review 19, 90-118.

15. K. D. Brouthers, L. E. Brouthers and T. J. Wilkinson, Strategic alliances: choose your partners Long Range Planning 28, $18-25$. 
16. Y. L. Doz, Technology partnerships between larger and smaller firms: some critical issues in F. J. Contractor and P. Lorange (eds) Cooperative Strategies in International Business Lexington Books, Lexington (1988).

17. J. P. Killing, Understanding alliances: the role of task and organisational complexity in F. J. Contractor and P. Lorange (eds) Cooperative Strategies in International Business Lexington Books, Lexington (1988).

18. P. J. Lane and M. Lubatkin, Relative absorptive capacity and inter-organisational learning Strategic Management Journal 19, 461-477.

19. G. Hamel, Competition for competence and inter-partner learning within international strategic alliances Strategic Management Journal 12, 83-103.

20. R. E. Spekman, L. A. Isabella, T. C. MacAvoy and T. Forbes III, Creating strategic alliances which endure Long Range Planning 29, 346-357.

21. J. Draulans, A. P. de Man and H. Volberda, Alliantievaardigheid: Een bron van concurrentievoordeel (Alliance capabilities: a source of competitive advantage) Holland/Belgium Management Review 63, 52-59. 